8-3-2021

\title{
Resilience and its associated factors in head and neck cancer patients in Pakistan: An analytical cross-sectional study
}

Nida Zahid

Wajeeha Zahid

Wardah Khalid

Syed lqbal Azam

Mubasher Ikram

See next page for additional authors

Follow this and additional works at: https://ecommons.aku.edu/pakistan_fhs_mc_surg_surg

Part of the Clinical Epidemiology Commons, Oncology Commons, Otolaryngology Commons, Otorhinolaryngologic Diseases Commons, and the Surgery Commons 


\section{Authors}

Nida Zahid, Wajeeha Zahid, Wardah Khalid, Syed Iqbal Azam, Mubasher Ikram, Aneesa Hassan, Haissan Iftikhar, Shireen Shehzad Bhamani, Adnan Jabbar, Shabbir Akhtar, Moghira Siddiqui, Mohammad Sohail Awan, Nargis Asad, and Khabir Ahmad 


\title{
Resilience and its associated factors in head and neck cancer patients in Pakistan: an analytical cross-sectional study
}

Nida Zahid ${ }^{1}$, Wajeeha Zahid², Wardah Khalid', Iqbal Azam², Mubasher Ikram, Aneesa Hassan', Haissan Iftikar ${ }^{1}$, Shireen Shehzad Bhamani ${ }^{3}$, Adnan Abdul Jabbar ${ }^{4}$, Shabbir Akhtar ${ }^{1}$, Moghira Iqbaluddin Siddiqui', Mohammad Sohail Awan', Nargis Asad ${ }^{5}$ and Khabir Ahmad ${ }^{1}$

\begin{abstract}
Introduction: The study aimed to assess resilience and its associated factors in head and neck cancer patients, post-treatment in a low middle income country (LMIC) such as Pakistan.

Methods: An analytical cross-sectional study was conducted from November 2019 to May 2020 among head and neck cancer patients aged at least 18 years at the largest private tertiary care hospital, in Karachi, Pakistan. Information regarding their resilience scores was collected through Wagnild and Young's Resilience scale that comprises of 14 items (RS-14). Moreover, depression and anxiety were also assessed via Hospital Anxiety and Depression Scale (HADS) and social support was assessed by Enriched Social Support Instrument (ESSI).

Results: The data was analyzed by linear regression modeling. Unadjusted and adjusted beta coefficients with $95 \%$ $\mathrm{Cl}$ were reported. A total of 250 head and neck cancer patients were recruited, $79 \%$ of them were males. Mean age of the patients was 51.59 years with $93 \%$ having high social support and only $8 \%$ having severe depression and 3\% having severe anxiety. After adjusting for the covariates in multivariable analysis resilience was associated with severe depression $(-17[-20.98,-12.93])$ or borderline depression $(-4[-8.41,-0.39])$, severe anxiety $(-11[-17.88,-$ $4.18])$, low social support $(-6[-9.62,-1.71])$, having family members of $>6$ in the household $(-2[-4.31,-0.29)$, smokeless tobacco users post- treatment $(10[5.79,14.45])$, and those who underwent tracheotomy $(-4[-7.67,-0.21])$. There was a significant interaction between education and role in the family (decision maker).

Conclusion: In Pakistan, a South Asian LMIC, collectivist culture prevails, family ties are greatly promoted thus resilience and social support is highly prevalent in head and neck cancer patients resulting in lower prevalence of depression and anxiety. Our study highlights that higher resilience is prevalent among small families less than six members, as the welfare of the individual is prioritized over multiple needs of the family. Formal Education and role in household/decision making power are effect modifiers in our study, demonstrating its protective effect on the mental health of head and neck cancer patients. High resilience scores were reported among current smokeless tobacco users as compared to quitters post treatment. Resilience-building interventions should be formulated to aid head and neck cancer patients to cope with the disease and its sequel.
\end{abstract}

\footnotetext{
* Correspondence: wajeeha.zahid@aku.edu

${ }^{2}$ Department of Community Health Sciences, Aga Khan University Hospital,

Stadium Road, Karachi 74800, Pakistan

Full list of author information is available at the end of the article
}

\section{$\triangle B M C$}

(c) The Author(s). 2021 Open Access This article is licensed under a Creative Commons Attribution 4.0 International License, which permits use, sharing, adaptation, distribution and reproduction in any medium or format, as long as you give appropriate credit to the original author(s) and the source, provide a link to the Creative Commons licence, and indicate if changes were made. The images or other third party material in this article are included in the article's Creative Commons licence, unless indicated otherwise in a credit line to the material. If material is not included in the article's Creative Commons licence and your intended use is not permitted by statutory regulation or exceeds the permitted use, you will need to obtain permission directly from the copyright holder. To view a copy of this licence, visit http://creativecommons.org/licenses/by/4.0/ The Creative Commons Public Domain Dedication waiver (http://creativecommons.org/publicdomain/zero/1.0/) applies to the data made available in this article, unless otherwise stated in a credit line to the data. 
Keywords: Anxiety, Developing countries, Depression, Head and neck cancer, mental health, Psycho-oncology, Resilience, Social support, Oncology

\section{Introduction}

Cancer is the leading cause of mortality in the developed world and second most common in developing countries [1]. Head and neck cancers ranks sixth with approximately 630,000 diagnosis, causing 350,000 deaths annually [2] with cancer of oral cavity being the highest contributor to its prevalence [3]. The risk of developing head and neck cancer increases 10 fold among habitual tobacco users than non-users [4]. The highly prevalent consumption of smokeless tobacco in our part of the world further adds to these numbers ranking it as the second most common cancer in Pakistan [5, 6]. The frequent consumption of pan, gutka, supari which contains highly carcinogenic products such as betel quid, areca nut (with or without tobacco), slaked lime, pre-disposes our population to oral cancer [7] with approximately 18,880 new cases annually. Lip and oral cavity cancer account for majority of the head and neck cancers in Pakistan having higher incidence in males $(15.9 \%$ new cases) in comparison to females [5].

Head and neck cancer surgeries are mutilating, leaving both physical and functional defects which have a huge bearing on a patients' psychosocial well-being resulting in anxiety and depression [8] which in turn leads to low resilience $[9,10]$. Resilience is the ability of an individual to positively adapt and maintain or regain emotional stability while experiencing an adverse condition [11]. Resilience might depend on several factors including positive emotions, cognitive flexibility (such as acceptance), active coping style, and spirituality etc. Resilience has shown to play a protective role against distress in cancer patients [12-16]. If improved psychological wellbeing is considered an endpoint of medical care along with survival, mortality, morbidity then resilience could be considered as a fulcrum between cancer symptoms and patient distress [17]. According to recent data, the prevalence of head and neck cancer is escalating in Pakistan, and limited information is available regarding resilience of head and neck cancer in our setting, a low middle-income country (LMIC) having diverse cultural, social and economic factors [18]. This study will bridge this gap and its findings would be beneficial in formulating targeted interventions as per need to improve resilience.

The aim of the study is to determine resilience in head and neck cancer patients at a tertiary care hospital in Pakistan, and to investigate its relationship with patients' socio-demographic factors, clinical characteristics, social support, and mental health.

\section{Methods \\ Study design}

An analytical cross-sectional study was conducted from November 2019 to May 2020 among head and neck cancer patients aged at least 18 years at Aga Khan University Hospital (AKUH), the largest private tertiary care hospital, in Karachi, Pakistan. At one point in time, data on resilience (outcome variable) and other predictor variables were obtained from head and neck cancer patients. The information was gathered on a structured questionnaire on the patients' socio-demographic characteristics, and validated instruments were used to evaluate the head and neck cancer patients' resilience, depression, anxiety, and social support status.

\section{Study participants}

Head and neck cancer patients, 18 years and above, currently $\geq 4$ weeks post-initiation of treatment at AKUH, living in Pakistan since the past 3 months and who provided written informed consent were included in the study. We excluded patients with physical comorbidities, (stroke, renal failure), as these debilitating diseases would distort the study results. Patients suffering from any known psychotic disorders (eg, manic disorder, schizophrenia etc), that lead to cognitive inability or require medication (such as antidepressants) were excluded. Patients with co-morbidities such as Cardiovascular Diseases (CVD), Diabetes Mellitus or Chronic Obstructive Pulmonary Disease (COPD) weren't excluded as their prevalence in Pakistani population is very high- [19] and their ineligibility would hinder in achieving the required sample size, therefore these confounders were adjusted during analysis [20].

\section{Sample size and sampling strategy}

Nonprobability purposive sampling technique was employed for selecting the patients. During the study period of November 2019 to May 2020, trained research assistants approached all head and neck cancer patients visiting the surgical/oncology clinics at AKUH as per their scheduled appointments. Potential participants were screened for eligibility by trained research assistants. The eligible participants were briefed on the scope and nature of the study, as well as the extent of their participation. Patients who provided written informed consent for participation were enrolled in the study and the study questionnaire was administered to them by the research assistants. The questionnaire was administered to each patient for about 30 to $40 \mathrm{~min}$. 
The minimum sample size was calculated to be 250 based on mean resilience scores for head and neck cancer patients from previous studies [21-25]. It was calculated using one population mean formula, based on a SD range of $16.5-40.8,5 \%$ level of significance with precision of 2.5 , and adding non-response of $10 \%$.

\section{Data collection}

Prior to participant recruitment, the questionnaire was pretested on $5 \%$ of the sample size to identify any ambiguities. The final questionnaire was administered by research assistants in Urdu (Pakistan's national and official language), and it was divided into three sections:

\section{Outcome variable Resilience}

Data regarding resilience was collected through the validated Urdu version of the Wagnild and Young's Resilience scale comprising of 14 items (RS-14), and each item was assigned a 7-point likert scale ranging from 1 (strongly disagree) to 7 (strongly agree). The RS-14 assessed five core characteristics of resilience; purposeful life, perseverance, equanimity, self-reliance and existential loneliness [26]. Its test-retest correlation coefficient was 0.49 and Cronbach's alpha was 0.76 . The concurrent validity was 0.813 [27].

\section{Predictors}

\section{Socio-demographic and clinical characteristics}

The questionnaire addressed patients' age, gender, ethnicity, education, family status, comorbidities conditions (hypertension, diabetes, cardiovascular disease), history of addictions (including smoking, substance abuse), employment status of patient and family members and monthly household income. Data on major recent life altering events was collected. Data regarding clinical characteristics; type of tumor, surgery, chemotherapy and/or radiotherapy and site of tumor was also collected.

\section{Psychosocial characteristics}

Data regarding depression and anxiety was collected via the validated Urdu version of Hospital Anxiety and Depression Scale (HADS) which comprises of 14 items, equally subdivided into the anxiety and depression subscales with each item scored from 0 to 3 [28, 29]. An individual who scored 8 to 10 was classified as mildly anxious and depressed whereas the one scoring at least 11 was classified as anxious and depressed.

Data regarding social support (functional and emotional) was collected through the validated Urdu version of Enriched Social Support Instrument (ESSI) [9] with a CVI for relevance of 0.95, clarity of 0.97, and Cronbach's alpha of 0.82 [30]. It comprises of 7 items and an aggregate score of at most 18 was considered as low social support.

\section{Plan of analysis}

The data was analyzed on STATA version 15. Continuous variables were reported as mean \pm standard error $(\mathrm{SE}) /$ median (IQR), while categorical variables were reported as frequency and percentages. Linear regression was used to report unadjusted and adjusted beta coefficients with $95 \% \mathrm{CI}$, to determine the factors associated with resilience among head and neck patients. The dependent variable was resilience. The independent variables were demographic variables (age, gender, monthly income, working status), comorbidities (hypertension, diabetes Mellitus, CVD), addictive substance use (tobacco and alcohol use), family history of cancer, tumorand treatment-related factors (type of tumor, type of surgical intervention, and adjuvant therapy), social support, depression and anxiety. The plausible interaction that we assessed was formal schooling and role in the family. A $p$-value $<0.05$ was considered significant for all analyses.

\section{Ethical considerations}

The study was approved by the Ethical Review Committee of the Aga Khan University Hospital. Written informed consent was obtained from all the study participants. All the patients' information was kept confidential and no personal identifier was disclosed. Participants identified as depressed via the Hospital Anxiety and Depression Scale (HADS) were provided on-thespot counseling by a trained psychologist. Whereas, those identified with severe depression (having suicidal thoughts) were referred to seek advice of a psychiatrist.

\section{Results}

\section{Description of the study participants}

The Table 1 describes the socio-demographic factors, co-morbidities, addictive use, family history, tumor related factors, social support and mental health of the head and neck cancer survivors. The mean age of the participants was $51.59(0.83)$ with $79 \%$ males. $87 \%$ of the participants had acquired formal education and mean years of schooling was $11.25(0.23)$ years. The mother tongue of about $50 \%$ of the participants was Urdu. Majority $(87 \%)$ of the participants were married and $53 \%$ of them lived in extended families. About $52 \%$ of the participants had $\leq 6$ household family members while $48 \%$ had more than 6 family members. 55\% of the participants were head / decision makers of the family. More than half $(64 \%)$ of the participants were not currently working and about $73 \%$ participants spouse were not employed. The median household monthly income was 
Table 1 Description of Head and Neck Cancer Survivors ( $n=$ 250)

\begin{tabular}{ll}
\hline Participants' Sociodemographic Characteristics \\
\hline Variables & $\boldsymbol{N}=\mathbf{2 5 0}$ \\
& $\mathbf{N}(\%) /$ Mean \pm SE \\
\hline Age (years) & $51.59 \pm 0.83$ \\
Gender & \\
$\quad$ Male & $198(79.2)$ \\
Female & $52(20.8)$
\end{tabular}

Formal Schooling

Yes

No

Informal Schooling

Yes

No

Type of Informal Schooling

Madrassa

Self-Learnt (reading)

Learnt Quran

Multiple

Mother Tongue

Urdu

Sindhi

Punjabi

Pushto

Memoni

Baloch

Kachi

Other

Marital Status

Married

Single

Other

Family Structure

Extended

Nuclear

Role in Family

$\begin{array}{ll}\text { Head/Chief Decision-Maker } & 138(55.2) \\ \text { Not Head; involved in decisions } & 98(39.2) \\ \text { Not Head; not involved in decisions } & 14(5.6) \\ \text { Number of Members in Family } & \end{array}$

$$
\leq 6
$$

$>6$

Working Status

Working

Not Working

Spouse's Working Status
$129(51.6)$

$121(48.4)$

$218(87.2)$

$32(12.8)$

69 (27.6)

$181(72.4)$

$N=69$

42(60.9)

$2(2.9)$

21 (30.4)

$4(5.8)$

$117(46.8)$

46 (18.4)

$14(5.6)$

$10(4.0)$

$16(6.4)$

$12(4.6)$

$7(2.8)$

$21(8.4)$

$218(87.2)$

$14(5.6)$

$18(7.2)$

$134(53.6)$

$116(46.4)$

$38(55.2)$

89 (35.6)

$161(64.4)$

$N=218$
Table 1 Description of Head and Neck Cancer Survivors ( $n=$ 250) (Continued)

\begin{tabular}{|c|c|}
\hline \multicolumn{2}{|l|}{ Participants' Sociodemographic Characteristics } \\
\hline Variables & $\begin{array}{l}N=250 \\
N(\%) / \text { Mean } \pm S E\end{array}$ \\
\hline Working & $36(16.5)$ \\
\hline Not Working & $182(83.5)$ \\
\hline \multicolumn{2}{|l|}{ Monthly Household Income (PKR/USD) } \\
\hline No Income & $18(7.2)$ \\
\hline $2000-25,000(\$ 13-\$ 151)$ & $40(16.0)$ \\
\hline $25,000-40,000(\$ 151-\$ 242)$ & $26(10.4)$ \\
\hline $40,000-80,000(\$ 242-\$ 484)$ & $69(27.6)$ \\
\hline $80,000-170,000(\$ 484-\$ 1028)$ & $97(38.8)$ \\
\hline Household Income (PKR/USD) & $\begin{array}{l}45,000(22650-100,000) / \\
281(142-625)\end{array}$ \\
\hline \multicolumn{2}{|l|}{ Comorbidities } \\
\hline Hypertension (HTN) & $64(25.6)$ \\
\hline Diabetes (DM) & $39(15.6)$ \\
\hline Cardiovascular Disease (CVD) & $10(4.00)$ \\
\hline Undergone any disease & $63(25.2)$ \\
\hline \multicolumn{2}{|l|}{ Addictive use Smoked tobacco users } \\
\hline Current & $5(2.4)$ \\
\hline Ex & $59(23.6)$ \\
\hline No & $185(74.0)$ \\
\hline \multicolumn{2}{|l|}{ Smokeless tobacco users } \\
\hline Current & $14(5.6)$ \\
\hline Ex & $103(41.2)$ \\
\hline No & $133(53.2)$ \\
\hline \multicolumn{2}{|l|}{ Family History of Cancer } \\
\hline Family history of head and neck cancer & $32(12.8)$ \\
\hline $\begin{array}{l}\text { Family History of any cancer other than } \\
\text { head and neck cancer }\end{array}$ & $38(15.2)$ \\
\hline Family history of depression & $10(4.0)$ \\
\hline
\end{tabular}

PKR Pakistani Rupee

USD US Dollars

PKR 45000 (22650-100,000) and 20\% of the participants had their own business.

We observed that 26\% had hypertension, $15 \%$ had Diabetes and $4 \%$ had CVD. About $2.4 \%$ of the participants were current smokers and 6\% were current smokeless tobacco users, however $24 \%$ were ex-smokers and $41 \%$ were ex smokeless tobacco users. 13\% of the participants had a family history of head and neck cancer while $15 \%$ had family history of other type of cancers. Only $4 \%$ of the participants had a family history of depression. $7 \%$ of the participants reported death in their family in the last 6 months.

Table 2 indicates the tumor and treatment related factors. Majority of the participants $(82 \%)$ had oral cancer. $41 \%$ had feeding tube while $8 \%$ had tracheotomy. 
Table 2 Tumor- and Treatment-related Factors

\begin{tabular}{ll}
\hline Variables & $\mathbf{N}=\mathbf{2 5 0} \mathbf{N}(\%)$ \\
\hline Tumor Type & $205(82)$ \\
Oral Cancer & $35(21.2)$ \\
Laryngeal & $10(4.0)$ \\
Others & \\
Surgical Intervention & $187(74.8)$ \\
Only Biopsy & $7(2.8)$ \\
Only Total Resection & $4(1.6)$ \\
Multiple Interventions & $52(20.8)$ \\
$\quad$ No surgical intervention & \\
Adjuvant Therapy & $12(4.8)$ \\
Chemotherapy & $46(18.4)$ \\
Radiotherapy & $132(52.8)$ \\
Combination & $60(24.0)$ \\
No Adjuvant Therapy & \\
Treatment Stage for head and neck cancer & $108(43.2)$ \\
On-going & $142(56.8)$ \\
Complete & $104(41.6)$ \\
Feeding Tube Needed & $19(7.6)$ \\
Tracheostomy Needed &
\end{tabular}

Majority of the participants (53\%) received combination adjuvant therapy (chemotherapy and radiotherapy).

Table 3 shows the social support, mental health and resilience among the head and neck cancer patients. We observed that $7 \%$ of the participants had low social

Table 3 Social Support, Mental Health and Resilience

\begin{tabular}{|c|c|}
\hline Variables & $\begin{array}{l}N=250 \\
N(\%) / \text { Mean } \pm \text { SE }\end{array}$ \\
\hline \multicolumn{2}{|l|}{ Social Support } \\
\hline$\leq 18$ (Low Social Support) & $18(7.2)$ \\
\hline > 18 (High Social Support) & $232(92.8)$ \\
\hline \multicolumn{2}{|l|}{ Depression } \\
\hline 0-7 (Normal) & $215(86.0)$ \\
\hline 8-10 (Mild Depression) & $16(6.4)$ \\
\hline 11-21 (Symptomatic Depression) & $19(7.6)$ \\
\hline \multicolumn{2}{|l|}{ Anxiety } \\
\hline 0-7 (Normal) & $237(94.8)$ \\
\hline 8-10 (Mild Anxiety) & $7(2.8)$ \\
\hline 11-21 (Symptomatic Anxiety) & $6(2.4)$ \\
\hline Resilience & $8(3.2)$ \\
\hline < 65 (Low Resilience) & 79 (31.6) \\
\hline $\begin{aligned} & 65-81 \text { (Moderate Resilience) } \\
> & 81 \text { (High Resilience) }\end{aligned}$ & $163(65.2)$ \\
\hline Resilience & $81.57 \pm 0.65$ \\
\hline
\end{tabular}

support. Moreover, 6\% reported borderline depression and $8 \%$ had severe depression. $3 \%$ of the participants had borderline anxiety and 3\% had severe anxiety. The mean resilience score was $82 \pm 0.65$.

\section{Univariate and multivariable analysis to assess resilience and its associated factors among head and neck cancer survivors}

The Table 4 shows the univariate and multivariable analysis to assess resilience and its associated factors among head and neck cancer survivors.

On univariate analysis (Table 4a) we observed that the resilience score was 3 units lower among participants with no formal education versus those with formal education. The resilience score of participants who were not head/not decision maker of the family was 5 units lower as compared to those who were the head/decision makers of the family. We also observed that the resilience score were 0.2 units lower among participants with household members more than 6 versus those with less than equal to 6. Smokeless tobacco users had 10 units higher resilience score as compared to ex-users. Moreover, resilience scores of participants with a family history of cancer were 4 units lower as compared to those with no F/H of cancer. Similarly, participants with $\mathrm{F} / \mathrm{H}$ of depression had resilience score 6 units lower as compared to their counterparts. Participants with feeding tube and tracheotomy had resilience score 3 and 7 units lower as compared to those who did not respectively. Similarly, those with urine bag had resilience score 11 units lower as compared to those who did not. We also observed that the resilience score of participants with less social support were 11 units lower as compared to those who had high social support. Participants who were severely depressed had 21 units lower resilience scores as compared to those who did not have depression. Similarly, lower resilience scores were observed among those who were severely anxious as compared to those who were not anxious.

On Multivariable analysis (Table 4b) depression, anxiety, social support, family members in the household, smokeless tobacco users, tracheotomy and interaction between education and role in the family were significantly associated with resilience. After adjustment for the covariates we observed that the resilience scores of participants with more than 6 household family members was $2(95 \% \mathrm{CI}$; $-4.31,-0.29)$ units lower as compared to those with $\leq 6$ household family members. Moreover, the resilience score among current smokeless tobacco users was 10 (95\% CI; 5.79, 14.45) units higher as compared to ex smokeless tobacco users. Resilience score among participants with tracheotomy was 4 (95\% $\mathrm{CI} ;-7.67,-0.21)$ units lower as compared to those without it. In addition, resilience score among participants 
Table 4 Univariate and Multivariable Analysis to Assess Resilience and Its Associated Factors among Head and Neck Cancer Survivors $(n=250)$

\begin{tabular}{|c|c|c|c|c|c|}
\hline \multirow{2}{*}{ Variables } & & \multicolumn{2}{|c|}{ 4a.Univariate Analysis } & \multicolumn{2}{|c|}{ 4b. Multivariate Analysis } \\
\hline & & $\begin{array}{l}\text { Unadjusted Beta } \\
\text { Coefficient (SE) }\end{array}$ & $\begin{array}{l}\text { 95\% Confidence } \\
\text { Interval (Cl) }\end{array}$ & $\begin{array}{l}\text { Adjusted Beta } \\
\text { Coefficient (SE) }\end{array}$ & $\begin{array}{l}\text { 95\% Confidence } \\
\text { Interval (Cl) }\end{array}$ \\
\hline \multirow[t]{2}{*}{ Formal Schooling } & Yes (ref) & & & & \\
\hline & No & $-3.37(1.93)$ & $(-7.18,0.42) *$ & $-0.66(2.04)$ & $(-4.67,3.36)$ \\
\hline Years of schooling & & $0.24(0.18)$ & $(-0.11,0.60) *$ & NS & NS \\
\hline \multirow[t]{3}{*}{ Role in family } & $\begin{array}{l}\text { Head/ decision makers of the family } \\
\text { (ref) }\end{array}$ & - & - & - & - \\
\hline & $\begin{array}{l}\text { Not Head /decision makers of the } \\
\text { family }\end{array}$ & $2.41(1.34)$ & $(-0.288,5.05)^{*}$ & $1.86(1.11)$ & $(-0.33,4.05)$ \\
\hline & $\begin{array}{l}\text { Not head/ not the decision makers of } \\
\text { the family }\end{array}$ & $-4.59(2.84)$ & $(-10.21,1.01)^{*}$ & $0.67(2.41)$ & $(-4.07,5.42)$ \\
\hline \multirow{2}{*}{$\begin{array}{l}\text { Family members in } \\
\text { the household }\end{array}$} & Less than 6 (ref) & - & - & - & - \\
\hline & More than 6 & $-0.18(1.30)$ & $(-2.74,2.38)^{*}$ & $-2.30(1.02)$ & $(-4.31,-0.29)^{* * *}$ \\
\hline \multirow{2}{*}{$\begin{array}{l}\text { Cardiovascular } \\
\text { Disease }\end{array}$} & Yes & $4.3(3.30)$ & $(-2.20,10.80)^{*}$ & NS & NS \\
\hline & No (ref) & & & & \\
\hline \multirow{3}{*}{$\begin{array}{l}\text { Smokeless Tobacco } \\
\text { user }\end{array}$} & Yes & $9.71(2.86)$ & $(4.06,15.35)^{*}$ & $10.12(2.20)$ & $(5.79,14.45)^{* *}$ \\
\hline & No & $0.855(1.32)$ & $(-1.74,3.45)$ & $1.06(1.03)$ & $(-0.97,3.08)$ \\
\hline & Ex user (ref) & - & & - & \\
\hline \multirow{2}{*}{$\begin{array}{l}\text { Family History of any } \\
\text { cancer }\end{array}$} & Yes & $-4.15(1.79)$ & $(-7.67,-0.62)^{*}$ & NS & NS \\
\hline & No (ref) & & & & \\
\hline \multirow{2}{*}{$\begin{array}{l}\text { Family history of } \\
\text { depression }\end{array}$} & Yes & $-5.49(3.29)$ & $(-11.98,1.00)^{*}$ & NS & NS \\
\hline & No (ref) & & & & \\
\hline \multirow[t]{2}{*}{ Deaths in the family } & Yes & $3.81(2.50)$ & $(-1.11,8.74)^{*}$ & NS & NS \\
\hline & No (ref) & & & & \\
\hline \multirow{2}{*}{$\begin{array}{l}\text { Patient has Feeding } \\
\text { tube }\end{array}$} & Yes & $-2.90(1.30)$ & $(-5.47,-0.33)^{*}$ & NS & NS \\
\hline & No (ref) & & & & \\
\hline \multirow{2}{*}{$\begin{array}{l}\text { Patient has } \\
\text { tracheotomy }\end{array}$} & Yes & $-6.99(2.41)$ & $(-11.74,-2.24)^{*}$ & $-3.98(1.92)$ & $(-7.67,-0.21)^{* *}$ \\
\hline & No (ref) & - & - & - & - \\
\hline \multirow[t]{2}{*}{ Patient has urine bag } & Yes & $-10.66(7.26)$ & $(-24.96,3.64)^{*}$ & NS & NS \\
\hline & No (ref) & & & & \\
\hline \multirow[t]{4}{*}{ Adjuvant therapy } & Chemotherapy & $1.833(3.23)$ & $(-4.53,8.19)$ & & \\
\hline & Radiotherapy & $-0.52(2.00)$ & $(-4.46,3.42)$ & & \\
\hline & Combination & $-2.68(1.59)$ & $(-5.82,0.44)^{*}$ & NS & NS \\
\hline & No Adjuvant Therapy (ref) & - & - & & \\
\hline \multirow[t]{2}{*}{ Social Support } & $<=18$ low social support & $-10.67(2.42)$ & $(-15.44,-5.90)^{*}$ & $-5.66(2.01)$ & $(-9.62,-1.71)^{* *}$ \\
\hline & $>18$ high social support (ref) & - & - & - & - \\
\hline \multirow[t]{3}{*}{ Depression } & $0-7$ (normal) (ref) & - & - & - & - \\
\hline & 8-10(borderline abnormal) & $-7.32(2.17)$ & $(-11.60,-3.03)^{*}$ & $-4.39(2.03)$ & $(-8.41,-0.39)^{* *}$ \\
\hline & 11-21 (case abnormal) & $-21.80(2.01)$ & $(-25.76,-17.84)^{*}$ & $-16.95(2.04)$ & $(-20.98,-12.93)^{* *}$ \\
\hline \multirow[t]{3}{*}{ Anxiety } & $0-7$ (normal) (ref) & - & - & - & - \\
\hline & 8-10(borderline case) & $-7.77(3.67)$ & $(-15.01,-0.53)^{*}$ & $-6.58(2.97)$ & $(-12.43,-0.73)^{* *}$ \\
\hline & 11-21(case abnormal) & $-23.179(3.96)$ & $\begin{array}{l}(-30.983 \\
-15.375)^{*}\end{array}$ & $-11.03(3.47)$ & $(-17.88,-4.18)^{* *}$ \\
\hline $\begin{array}{l}\text { Formal schooling * } \\
\text { Role in the family }\end{array}$ & $\begin{array}{l}\text { Formal schooling * Head/ decision } \\
\text { makers of the family (ref) }\end{array}$ & & & - & - \\
\hline
\end{tabular}


Table 4 Univariate and Multivariable Analysis to Assess Resilience and Its Associated Factors among Head and Neck Cancer Survivors $(n=250)$ (Continued)

\begin{tabular}{|c|c|c|c|c|c|}
\hline \multirow[b]{2}{*}{ Variables } & & \multicolumn{2}{|c|}{ 4a.Univariate Analysis } & \multicolumn{2}{|c|}{ 4b. Multivariate Analysis } \\
\hline & & $\begin{array}{l}\text { Unadjusted Beta } \\
\text { Coefficient (SE) }\end{array}$ & $\begin{array}{l}\text { 95\% Confidence } \\
\text { Interval (CI) }\end{array}$ & $\begin{array}{l}\text { Adjusted Beta } \\
\text { Coefficient (SE) }\end{array}$ & $\begin{array}{l}\text { 95\% Confidence } \\
\text { Interval (CI) }\end{array}$ \\
\hline & $\begin{array}{l}\text { No formal schooling * Not the head/ } \\
\text { decision makers of the family }\end{array}$ & NA & NA & $-0.32(3.08)$ & $(-5.76,6.39)$ \\
\hline & $\begin{array}{l}\text { No Formal schooling * Not head/ not } \\
\text { decision makers of the family }\end{array}$ & & & $-16.45(5.40)$ & $(-27.08,-5.82)^{* *}$ \\
\hline
\end{tabular}

$\mathrm{R}^{2}=0.49$

*Significant at $p$ value $<0.025$ by univariate linear regression

** Significant at $p$ value $<0.05$ by multivariable linear regression

NS (non-significant)

NA (not-applicable)

with low social support was 6 (95\% CI; - 9.62,-1.71) units lower as compared to those with high social support. Moreover, resilience score among participants with severe depression was 17 (95\% CI; - 20.98,-12.93) units lower as compared to non depressed, similarly, resilience score among those with borderline depression was 4 (95\% CI; - 8.41,-0.39) units lower as compared to those who were not depressed. Resilience scores of participants with severe anxiety was 11 (95\% CI; - 17.88,-4.18) units lower as compared to those with no anxiety, similarly, resilience score of those with mild anxiety was $7(95 \% \mathrm{CI} ;-12.43,-0.73)$ units lower as compared to those who were not anxious. There was a significant interaction between formal education and role in the family. Resilience score of participants who acquired no formal education and were not the head/ decision makers of the family was 16 (95\% CI; - 27.08, - 5.82) units lower as compared to those who had formal education and were the head/ decision makers of the family.

\section{Discussion}

This study aimed to assess the resilience of head and neck cancer survivors and its associated factors in Pakistani population. In our study population social support, number of family members in household, tracheotomy, depression, anxiety and smokeless tobacco were significantly associated with resilience.

In the present study we found an association between social support and high resilience. In Pakistan collectivistic culture prevails where family ties are greatly promoted. Social support provided by family members and healthcare professionals together help cancer patients in coping with the downside of their condition. It buffers against the negative impact of stress [31] instills hope and has positive effect on increase in lifespan [32, 33] which in turn promotes resilience [34]. Few studies report that during the ailment friends and family drift away [35] whilst others report that optimistic nature and adaptive coping strategies of patient fosters social support [36]. Pinar G et al. [31] and Brix et al. [37] found that there was negative association between need for psychosocial support and resilience as individuals with low resilience need psychosocial support in comparison to those having high resilience. Resilience plays protective role by minimizing the negative impact of distress $[38,39]$. In our study participants with severe and borderline depression had lower resilience scores. Similarly participants with severe anxiety had lower resilience scores in comparison to those with mild anxiety or those who weren't anxious. Brian et al. suggests that head and neck cancer patients should be routinely screened for depression and treated at the earliest to improve resilience [40].

Resilience was higher in cancer survivors having less than 6 household family members than those with at least 6 family members living with them. This finding is comparable to Narchal et al. [41] who also reported that small families comprising of 4 to 5 individuals have stronger family ties in comparison to those having large family size. The resilience of the family eases the burden on the principal caregiver and promotes the resilience of the cancer survivor [42]. In Pakistan the joint family system is more common where two or three generations reside under one roof [43]. With more family members living in the household the chances of emotional disclosure is higher than in nuclear family structures which might result in higher resilience [44] but at the same time large families residing in one household have multiple needs [45].

Resilience was lower in cancer survivors who had tracheotomy tube (to secure airway or difficulty with secretions) than those who did not. Tracheotomy adversely impacts the life of cancer survivors as their daily physical activities are restricted, speech is limited, physical 
appearance is altered and tracheostomy tube requires constant care. As dyspnea increases in head and neck cancer patients there is a dip in their resilience [46]. In contrast studies report that post treatment resilience improves significantly with every passing year as cancer survivors adapt to this new way of life [47-49]. In view of these findings it's important that patients with tracheostomy are brought to a level where they can perform self-care [50].

Another finding of this study is that among cancer survivors the resilience score is higher among current smokeless tobacco users as compared to those who quit smokeless tobacco post treatment The findings of our study were consistent with those of an Indian study that found a significant positive correlation between smokeless tobacco use and QoL and a negative correlation with distress among head and neck cancer patients after treatment [51]. The plausible explanation of this could be that some cancer survivors manage anxiety of cancer recurrence by continuing tobacco consumption post cancer treatment as a coping strategy [52].

Formal education and decision maker of the family were seen as effect modifiers. The association of formal education and resilience varies by level of this third factor, role in the household decision-making process. Pakistan being a patriarchal society, where men hold greater authority in the household, women have limited decision making power but education has significant effect on decision-making power in the household irrespective of gender. Formal education results in a better job in turn more contribution to the household expenses thus an elevated role in the decision-making of the household resulting in higher resilience [52].

\section{Limitations and strengths}

The strength of our study was that the data collectors were trained psychologist and provided on the spot counseling to patients identified as mildly anxious or depressed whereas those with symptomatic anxiety or depression were referred to seek advice from a psychiatrist. The setting of our study is Aga Khan University Hospital (AKUH), Karachi, the largest private tertiary care hospital in the largest metropolitan city of our country that caters to diverse ethnicities and socioeconomic groups thus a representative sample generalizing our findings.

There were some limitations in the present study, because of the cross sectional design temporality between resilience and mental health in head and neck cancer patients couldn't be established. Longitudinal studies are needed to explore the association of resilience and mental health during the course of cancer treatment.

\section{Conclusion}

In Pakistan, a South Asian LMIC, collectivist culture prevails, family ties are greatly promoted thus resilience and social support is highly prevalent in head and neck cancer patients resulting in lower prevalence of depression and anxiety. Our study highlights that higher resilience is prevalent among small families, less than six members, as the welfare of the individual is prioritized over multiple needs of the family. Formal Education and role in household/decision making power are effect modifiers in our study, demonstrating protective effect on mental health in head and neck cancer patients. High resilience scores were reported among current smokeless tobacco users as compared to quitters post treatment. Resilience-building interventions should be formulated to aidhead and neck cancer patients to cope with the disease and its sequelae.

\section{Abbreviations}

LMIC: Lower and Middle Income Country; AKUH: Aga Khan University Hospital; CVD : Cardiovascular Disease; COPD : Chronic Obstructive Pulmonary Disease; RS-14: Resilience Scale 14; HADS: Hospital Anxiety and Depression Scale; ESSI: Enriched Social Support Instrument; CVI : Content Validation Index; IQR : Interquartile range

\section{Supplementary Information}

The online version contains supplementary material available at https://doi. org/10.1186/s12885-021-08624-8.

\section{Additional file 1.}

\section{Acknowledgements}

We would like to acknowledge our research associateBarka Raj, and secretarial support, Mr. Mirza Anas. We would like to acknowledge Wagnild for allowing us to use Wagnild and Young's Resilience Scale.

\section{Original publication}

This manuscript has not been submitted or is not under consideration for publication elsewhere. The protocol of the study is published in BMJ Open (doi: https://doi.org/10.1136/bmjopen-2019-029084)

Authors' contributions

NZ conceived the study, analyzed data, and critically reviewed the manuscript. WZ drafted, revised, and critically reviewed the manuscript. IA contributed to data analysis. WK, AH, HI, SSB, NA and KA overlooked the study and intellectually contributed to the manuscript. AAJ, SA, MIS, MSA and $\mathrm{MI}$ were the subject experts. All authors have contributed intellectually to this manuscript, and have read and approved the final manuscript.

\section{Funding}

The study is funded by Aga Khan University Seed Money Fund (Grant Number PF98/0417).

Availability of data and materials

The data that support the findings of this study are available from the corresponding author upon reasonable request.

\section{Declarations}

Ethics approval and consent to participate

Ethical approval was obtained from Ethical Review Committee of the Aga Khan University Hospital, Karachi, Pakistan. Written informed consent was obtained from all the study participants. All methods were performed in accordance with the Declaration of Helsinki. 


\section{Consent for publication}

Consent to was obtained from the participants to publish.

\section{Competing interests}

No Potential conflict of interest exist.

\section{Author details}

'Department of Surgery, Aga Khan University Hospital, Stadium Road, Karachi 74800, Pakistan. ${ }^{2}$ Department of Community Health Sciences, Aga Khan University Hospital, Stadium Road, Karachi 74800, Pakistan. ${ }^{3}$ School of Nursing and Midwifery, Aga Khan University Hospital, Stadium Road, Karachi 74800, Pakistan. ${ }^{4}$ Department of Oncology, Aga Khan University Hospital, Stadium Road, Karachi 74800, Pakistan. ${ }^{5}$ Department of Psychiatry, Aga Khan University Hospital, Stadium Road, Karachi 74800, Pakistan.

Received: 22 December 2020 Accepted: 5 July 2021

Published online: 03 August 2021

\section{References}

1. Ferlay J, Soerjomataram I, Dikshit R, Eser S, Mathers C, Rebelo M, et al. Cancer incidence and mortality worldwide: sources, methods and major patterns in GLOBOCAN 2012. Int J Cancer. 2015;136(5):E359-E86. https://doi. org/10.1002/ijc.29210.

2. Gupta B, Johnson NW, Kumar N. Global epidemiology of head and neck cancers: a continuing challenge. Oncology. 2016;91(1):13-23. https://doi. org/10.1159/000446117.

3. Mummudi N, Agarwal J, Chatterjee S, Mallick I, Ghosh-Laskar S. Oral cavity cancer in the Indian subcontinent-challenges and opportunities. Clin Oncol. 2019:31(8):520-8. https://doi.org/10.1016/j.clon.2019.05.013.

4. Madani AH, Jahromi AS, Madhurima D, Debanshu B. Risk assessment of tobacco types and oral cancer. Am J Pharmacol Toxicol. 2010;5(1):9-13. https://doi.org/10.3844/ajptsp.2010.9.13.

5. Siddiqi K, Shah S, Abbas SM, Vidyasagaran A, Jawad M, Dogar O, et al. Global burden of disease due to smokeless tobacco consumption in adults: analysis of data from 113 countries. BMC Med. 2015;13(1):194. https://doi. org/10.1186/s12916-015-0424-2

6. Bilal S, Doss JG, Cella D, Rogers SN. Quality of life associated factors in head and neck cancer patients in a developing country using the FACT-H\&N. J Cranio-Maxillofac Surg. 2015;43(2):274-80. https://doi.org/10.1016/j.jcms.2 014.11 .024$.

7. Humans IWGotEoCRt. Betel-quid and areca-nut chewing and some arecanut-derived nitrosamines: IARC monographs on the evaluation of carcinogenic risks to humans. 2004;85:1. https://pubmed.ncbi.nlm.nih.gov/1 $5635762 /$

8. Singer S, Das-Munshi J, Brähler E. Prevalence of mental health conditions in cancer patients in acute care-a meta-analysis. Ann Oncol. 2010;21(5):92530. https://doi.org/10.1093/annonc/mdp515.

9. Kroenke K, Theobald D, Wu J, Loza JK, Carpenter JS, Tu W. The association of depression and pain with health-related quality of life, disability, and health care use in cancer patients. J Pain Symptom Manag. 2010;40(3):32741. https://doi.org/10.1016/j.jpainsymman.2009.12.023.

10. Weisman AD. A model for psychosocial phasing in cancer. Gen Hosp Psychiatry. 1979;1(3):187-95. https://doi.org/10.1016/0163-8343(79)90018-5.

11. Herrman H, Stewart DE, Diaz-Granados N, Berger EL, Jackson B, Yuen T. What is resilience? Can J Psychiatry. 2011;56(5):258-65.

12. Wu LM, Sheen JM, Shu HL, Chang SC, Hsiao CC. Predictors of anxiety and resilience in adolescents undergoing cancer treatment. J Adv Nurs. 2013; 69(1):158-66. https://doi.org/10.1111/j.1365-2648.2012.06003.x.

13. Ragnarsdóttir LD. Resilience in men with prostate cancer: relationship between resilience, social support, and distress; 2012.

14. Orom H, Nelson CJ, Underwood W III, Homish DL, Kapoor DA. Factors associated with emotional distress in newly diagnosed prostate cancer patients. Psycho-Oncology. 2015;24(11):1416-22. https://doi.org/10.1002/ pon.3751.

15. Min J-A, Yoon S, Lee C-U, Chae J-H, Lee C, Song K-Y, et al. Psychological resilience contributes to low emotional distress in cancer patients. Support Care Cancer. 2013;21(9):2469-76. https://doi.org/10.1007/s00520-013-1807-6.

16. Tian J, Hong J-S. Assessment of the relationship between resilience and quality of life in patients with digestive cancer. World J Gastroenterol. 2014; 20(48):18439-44. https://doi.org/10.3748/wjg.v20.i48.18439.
17. Fradelos EC, Papathanasiou IV, Veneti A, Daglas A, Christodoulou E, Zyga S, et al. Psychological distress and resilience in women diagnosed with breast cancer in Greece. Asian Pac J Cancer Prev. 2017;18(9):2545-50. https://doi. org/10.22034/APJCP.2017.18.9.2545.

18. Zahid N, Khalid W, Ahmad K, Bhamani SS, Azam I, Asad N, et al. Resilience and quality of life (QoL) of head and neck cancer and brain tumour survivors in Pakistan: an analytical cross-sectional study protocol. BMJ Open. 2019;9(9):e029084. https://doi.org/10.1136/bmjopen-2019-029084.

19. Degenhardt L, Whiteford HA, Ferrari AJ, Baxter AJ, Charlson FJ, Hall WD, et al. Global burden of disease attributable to illicit drug use and dependence: findings from the global burden of disease study 2010. Lancet. 2013;382(9904): 1564-74. https://doi.org/10.1016/S0140-6736(13)61530-5.

20. Kim GM, Lim JY, Kim EJ, Park SM. Resilience of patients with chronic diseases: a systematic review. Health Soc Care Community. 2019;27(4):797807. https://doi.org/10.1111/hsc.12620.

21. Leung SW, Lee T-F, Chien C-Y, Chao P-J, Tsai W-L, Fang F-M. Health-related quality of life in 640 head and neck cancer survivors after radiotherapy using EORTC QLQ-C30 and QLQ-H\&N35 questionnaires. BMC Cancer. 2011; 11(1):128. https://doi.org/10.1186/1471-2407-11-128.

22. Arillo-Santillan E, Lazcano-Ponce E, Hernandez-Avila M, Fernández E, Allen B, Valdes $\mathrm{R}$, et al. Associations between individual and contextual factors and smoking in 13,293 Mexican students. Am J Prev Med. 2005;28(1):41-51. https://doi.org/10.1016/j.amepre.2004.09.002.

23. Wu W-W, Tsai S-Y, Liang S-Y, Liu C-Y, Jou S-T, Berry DL. The mediating role of resilience on quality of life and cancer symptom distress in adolescent patients with cancer. J Pediatr Oncol Nurs. 2015;32(5):304-13. https://doi. org/10.1177/1043454214563758.

24. Talepasand S, Pooragha F, Kazemi M. Resiliency and quality of life in patients with cancer: moderating role of duration of awareness of cancer. Iran J Cancer Prev. 2013:6(4):222-6.

25. Rehman B, ud Din Q, Khan M, Noreen R. Evaluation of the quality of life in patients with oral squamous cell carcinoma. Cell. 2012:333:9199288.

26. Wagnild GM. The resilience scale user's guide: for the US English version of the resilience scale TM and the 14-item resilience scale TM (RS-14 TM): resilience center; 2009 .

27. Bhamani SS, Pasha O, Karmaliani R, Asad N, Azam I. Validation of the Urdu version of Wagnild and Young's long and short resilience scales among 20-to 40-year-old married women living in urban squatter settlements of Karachi, Pakistan. J Nurs Meas. 2015;23(3):425-35. https:/doi.org/10.1891/1061-3749.23.3.425.

28. Zigmond AS, Snaith RP. The hospital anxiety and depression scale. Acta Psychiatr Scand. 1983;67(6):361-70. https://doi.org/10.1111/j.1600-0447.1983.tb09716.x.

29. Mumford D, Tareen I, Bajwa M, Bhatti M, Karim R. The translation and evaluation of an Urdu version of the hospital anxiety and depression scale. Acta Psychiatr Scand. 1991;83(2):81-5. https://doi.org/10.1111/j.1600-0447.1991.tb07370.x.

30. Khalid W, Rozi S, Ali TS, Azam I, Mullen MT, Illyas S, et al. Quality of life after stroke in Pakistan. BMC Neurol. 2016;16(1):250. https://doi.org/10.1186/s12 883-016-0774-1.

31. Pinar G, Okdem S, Buyukgonenc $L$, Ayhan A. The relationship between social support and the level of anxiety, depression, and quality of life of Turkish women with gynecologic cancer. Cancer Nurs. 2012;35(3):229-35. https://doi.org/10.1097/NCC.0b013e31822c47bd.

32. Carver CS. Resilience and thriving: issues, models, and linkages. J Soc Issues. 1998:54(2):245-66. https://doi.org/10.1111/j.1540-4560.1998.tb01217.x.

33. Yoo GJ, Levine EG, Aviv C, Ewing C, Au A. Older women, breast cancer, and social support. Support Care Cancer. 2010;18(12):1521-30. https://doi.org/1 0.1007/s00520-009-0774-4.

34. Hou WK, Lam JHM. Resilience in the year after cancer diagnosis: a crosslagged panel analysis of the reciprocity between psychological distress and well-being. J Behav Med. 2014;37(3):391-401. https://doi.org/10.1007/s1 0865-013-9497-6.

35. Dedeli Ö, Fadıloğlu C, Uslu R. An investigation of functional situation and perceived social support of cancer patients. J Turk Oncol. 2008;23: 132-9.

36. Petersen LR, Clark MM, Novotny P, Kung S, Sloan JA, Patten CA, et al. Relationship of optimism-pessimism and health-related quality of life in breast cancer survivors. J Psychosoc Oncol. 2008;26(4):15-32. https://doi. org/10.1080/07347330802359578

37. Brix C, Schleussner C, Füller J, Roehrig B, Wendt TG, Strauss B. The need for psychosocial support and its determinants in a sample of patients undergoing radiooncological treatment of cancer. J Psychosom Res. 2008; 65(6):541-8. https://doi.org/10.1016/j.jpsychores.2008.05.010. 
38. Skrove M, Romundstad P, Indredavik MS. Resilience, lifestyle and symptoms of anxiety and depression in adolescence: the young-HUNT study. Soc Psychiatry Psychiatr Epidemiol. 2013;48(3):407-16. https://doi.org/10.1007/ s00127-012-0561-2.

39. Abrams MS. Resilience in ambiguous loss. Am Psychiatric Assoc. In.: Am Psychiatric Assoc; 2001. https://psychotherapy.psychiatryonline.org/doi/pdf/1 0.1176/appi.psychotherapy.2001.55.2.283.

40. Lin BM, Starmer HM, Gourin CG. The relationship between depressive symptoms, quality of life, and swallowing function in head and neck cancer patients 1 year after definitive therapy. Laryngoscope. 2012;122(7):1518-25. https://doi.org/10.1002/lary.23312.

41. Narchal R, Shukla JD. Family size and its effect on personality and adjustment. J Psychol Res. 1986.

42. Li Y, Wang K, Yin Y, Li Y, Li S. Relationships between family resilience, breast cancer sunvivors' individual resilience, and caregiver burden: a cross-sectional study. Int J Nurs Stud. 2018;88:79-84. https:/doi.org/10.1016/j.jnurstu.2018.08.011.

43. Baig N-u-A, Rehman RR, Mobeen N. A Parent-Teacher View of Teens Behaviors in Nuclear and Joint Family Systems in Pakistan. Qual Rep. 2014; 19(34):1-12.

44. Muzaffar N. Role of Family System, Positive Emotions and Resilience in Social Adjustment among Pakistani Adolescents. J Educ Health Community Psychol. 2017;6(2):46-58.

45. Buckle P. Assessing social resilience. Disaster resilience: An integrated approach; 2006. p. 88-103.

46. MacDonald CA. Minimizing the impact of disease while maximizing quality of life: an exploration of resilience in head and neck cancer survivors; 2017.

47. Hammerlid E, Mercke C, Sullivan M, Westin T. A prospective quality of life study of patients with laryngeal carcinoma by tumor stage and different radiation therapy schedules. Laryngoscope. 1998;108(5):747-59. https://doi. org/10.1097/00005537-199805000-00023.

48. Asare B. Life after tracheostomy: the experiences of adults in the Kumasi Metropolis. Ghana: University of Ghana; 2016.

49. Flynn A. A narrative inquiry into the stories parents tell of having a child with a tracheostomy: University of Central Lancashire; 2018.

50. Gul N, Karadag A. An evaluation of the quality of life in patients with tracheostomy. Pak J Med Sci. 2010;26(2):444-9.

51. Pandey M, Devi N, Ramdas K, Krishnan R, Kumar V. Higher distress relates to poor quality of life in patients with head and neck cancer. Int J Oral Maxillofac Surg. 2009;38(9):955-9. https://doi.org/10.1016/ij.jom.2009.04.004.

52. Sultana A. Factors effect on women autonomy and decision-making power within the household in rural communities. J Appl Sci Res. 2011;7(1):18-22.

\section{Publisher's Note}

Springer Nature remains neutral with regard to jurisdictional claims in published maps and institutional affiliations.

\section{Ready to submit your research? Choose BMC and benefit from:}

- fast, convenient online submission

- thorough peer review by experienced researchers in your field

- rapid publication on acceptance

- support for research data, including large and complex data types

- gold Open Access which fosters wider collaboration and increased citations

- maximum visibility for your research: over $100 \mathrm{M}$ website views per year

At BMC, research is always in progress.

Learn more biomedcentral.com/submissions 